\title{
TOTAL 2-RAINBOW DOMINATION NUMBERS OF TREES
}

\author{
H. Abdollahzadeh Ahangar ${ }^{1}$, J. Amjadi $^{2}$, M. Chellali $^{3}$, \\ S. NAZARI-Moghaddam ${ }^{2}$ And S.M. Sheikholeslami ${ }^{2}$ \\ ${ }^{1}$ Department of Mathematics \\ Babol Noshirvani University of Technology \\ Babol, I.R. Iran \\ e-mail: ha.ahangar@nit.ac.ir \\ ${ }^{2}$ Department of Mathematics \\ Azarbaijan Shahid Madani University \\ Tabriz, I.R. Iran \\ e-mail: j-amjadi;s.nazari;s.m.sheikholeslami@azaruniv.ac.ir \\ ${ }^{3}$ LAMDA-RO Laboratory, Department of Mathematics \\ University of Blida \\ B.P. 270, Blida, Algeria \\ e-mail: m_chellali@yahoo.com
}

\begin{abstract}
A 2-rainbow dominating function (2RDF) of a graph $G=(V(G), E(G))$ is a function $f$ from the vertex set $V(G)$ to the set of all subsets of the set $\{1,2\}$ such that for every vertex $v \in V(G)$ with $f(v)=\emptyset$ the condition $\bigcup_{u \in N(v)} f(u)=\{1,2\}$ is fulfilled, where $N(v)$ is the open neighborhood of $v$. A total 2-rainbow dominating function $f$ of a graph with no isolated vertices is a $2 \mathrm{RDF}$ with the additional condition that the subgraph of $G$ induced by $\{v \in V(G) \mid f(v) \neq \emptyset\}$ has no isolated vertex. The total 2-rainbow domination number, $\gamma_{t r 2}(G)$, is the minimum weight of a total 2-rainbow dominating function of $G$. In this paper, we establish some sharp upper and lower bounds on the total 2-rainbow domination number of a tree. Moreover, we show that the decision problem associated with $\gamma_{t r 2}(G)$ is NP-complete for bipartite and chordal graphs.
\end{abstract}

Keywords: 2-rainbow dominating function, 2-rainbow domination number, total 2-rainbow dominating function, total 2-rainbow domination number.

2010 Mathematics Subject Classification: 05C69. 


\section{REFERENCES}

[1] H. Abdollahzadeh Ahangar, J. Amjadi, N. Jafari Rad and V. Samodivkin, Total k-rainbow domination in graphs, Comm. Combin. Optim. 3 (2018) 37-50.

doi:10.22049/CCO.2018.25719.1021

[2] H. Abdollahzadeh Ahangar, M.A. Henning, V. Samodivkin and I.G. Yero, Total Roman domination in graphs, Appl. Anal. Discrete Math. 10 (2016) 501-517. doi:10.2298/AADM160802017A

[3] H. Abdollahzadeh Ahangar, M. Khaibari, N. Jafari Rad and S.M. Sheikholeslami, Graphs with large total 2-rainbow domination number, Iran. J. Sci. Technol. Trans. A Sci. 42 (2018) 841-846. doi:10.1007/s40995-017-0465-9

[4] G.J. Chang, J. Wu and X. Zhu, Rainbow domination on trees, Discrete Appl. Math. 158 (2010) 8-12. doi:10.1016/j.dam.2009.08.010

[5] M. Chellali and N. Jafari Rad, On 2-Rainbow domination and Roman domination in graphs, Australas. J. Combin. 56 (2013) 85-93.

[6] B. Brešar, M.A. Henning and D.F. Rall, Rainbow domination in graphs, Taiwanese J. Math. 12 (2008) 201-213.

[7] B. Brešar and T.K. Sumenjak, On the 2-rainbow domination in graphs, Discrete Appl. Math. 155 (2007) 2394-2400.

doi:10.1016/j.dam.2007.07.018

[8] N. Dehgardi, S.M. Sheikholeslami and L. Volkmann, The rainbow domination subdivision numbers of graphs, Mat. Vesnik 67 (2015) 102-114.

[9] E. DeLaVina, C.E. Larson, R. Pepper and B. Waller, On total domination and support vertices of a tree, AKCE Int. J. Graphs Comb. 7 (2010) 85-95.

[10] M. Falahat, S.M. Sheikholeslami and L. Volkmann, New bounds on the rainbow domination subdivision number, Filomat 28 (2014) 615-622. doi:10.2298/FIL1403615F

[11] C.-H. Liu and G.J. Chang, Roman domination on strongly chordal graphs, J. Comb. Optim. 26 (2013) 608-619. doi:10.1007/s10878-012-9482-y

[12] Y. Wu and N. Jafari Rad, Bounds on the 2-Rainbow domination number of graphs, Graphs Combin. 29 (2013) 1125-1133. doi:10.1007/s00373-012-1158-y

[13] Y. Wu and H. Xing, Note on 2-rainbow domination and Roman domination in graphs, Appl. Math. Lett. 23 (2010) 706-709. doi:10.1016/j.aml.2010.02.012 